\title{
Influence of Neonatal Practice Variation on Outcomes of Late Preterm Birth
}

\author{
Sofia Aliaga, MD, MPH ${ }^{1}$ Kim Boggess, MD² Thomas S. Ivester, MD, MPH ${ }^{2} \quad$ Wayne A. Price, MD ${ }^{1}$ \\ ${ }^{1}$ Department of Pediatrics, The University of North Carolina at Chapel \\ Hill, Chapel Hill, North Carolina \\ 2 Department of Obstetrics and Gynecology, The University of North \\ Carolina at Chapel Hill, Chapel Hill, North Carolina

\begin{abstract}
Address for correspondence Sofia Aliaga, MD, MPH, Department of Pediatrics, The University of North Carolina at Chapel Hill, 101 Manning Drive, CB \#7596, N4051, 4th Floor, UNC Hospitals, Chapel
\end{abstract} \\ Hill, NC 27599 (e-mail: saliaga@med.unc.edu).
}

Am J Perinatol 2014;31:659-666.

\begin{abstract}
Keywords

- late preterm

- practice variation

- neonatal care
\end{abstract}

Over $70 \%$ of preterm births each year in the United States, or approximately 400,000 newborns, are late preterm $\left(34^{0 / 7}-36^{6 / 7}\right.$ weeks' gestation $){ }^{1}$ Late preterm newborns experience greater morbidity and increased health care utilization compared with term newborns, including more frequent admission to a neonatal intensive care unit (NICU), longer birth hospitalizations, and increased readmission during the first 30 days after birth. ${ }^{2}$

Differences in hospital and provider practices contribute to variation in newborn care, including NICU admission, antibiotic use, length of stay, and costs. ${ }^{3-9}$ Data specific to the late preterm population is lacking. Late preterm newborns can be cared for in the routine newborn nursery or an intensive care unit, very different health care service environments. The

received

July 8,2013

accepted after revision

August 5, 2013

published online

September 10, 2013

need for intensive care at birth for the late preterm newborn is determined, in part, by the presence of clinical risk factors or disease. Other factors that influence the decision to admit a late preterm newborn to a NICU include the level of care available at the birth hospital, provider preferences, and institution-specific practices (e.g., gestational age or birth weight thresholds for NICU admission). ${ }^{10,11}$

Late preterm newborn care during the birth hospitalization, such as NICU admission and phototherapy, is likely to have implications for health care utilization after discharge (e.g., outpatient care and readmissions). Guidelines for the care of late preterm newborns include recommendations on criteria for discharge and follow-up, but evidence for the appropriate or "best" level of care or length of stay after birth

Copyright $\odot 2014$ by Thieme Medical Publishers, Inc., 333 Seventh Avenue, New York, NY 10001, USA. Tel: +1(212) 584-4662.
DOI http://dx.doi.org/ 10.1055/s-0033-1356484. ISSN 0735-1631. 
are lacking. ${ }^{2,10}$ The challenge of predicting an individual late preterm newborn's clinical needs at birth combined with institution and provider practice variation likely results in differences in the quality of care. The purpose of this study is to examine variation in newborn care and short-term outcomes of late preterm newborns across three hospitals.

\section{Methods}

We performed a cohort study from a prospectively collected random sample of late preterm births at three North Carolina hospitals from March 2008 to July 2009. These hospitals are within close geographic proximity. Subjects were eligible for the study if delivery occurred between $34^{0 / 7}$ and $36^{6 / 7}$ weeks' gestation on one of the randomly selected study days. Selection of study days equally sampled weekday and weekend days. Gestational age was determined by best obstetrical estimate. We excluded births resulting from multiple gestations, newborns with major congenital anomalies, and stillbirths. The study sites included a university teaching hospital, a teaching community hospital, and a nonteaching community hospital. Only the university teaching hospital required admission to the NICU for births $<35$ weeks' gestation or birth weight $<2,000$ g. The other study hospitals did not have gestational age or birth weight thresholds for mandatory NICU admission.

We reviewed medical records for data on maternal sociodemographics, medical and obstetrical history, labor and delivery, and neonatal outcomes for the birth hospitalization. Trained research nurses and the first author (S.A.) performed all data abstraction. We categorized births according to the obstetric or medical complication indicated as the primary reason for admission and/or indication for delivery: preterm premature rupture of membranes (PPROM)/spontaneous labor, hypertensive disorders of pregnancy, placenta previa/abruption, elective/ scheduled, or other. Study outcomes included length of stay, NICU admission, antibiotic exposure, phototherapy exposure, need for respiratory support, and hypoglycemia. We defined NICU admission as admission to the nursery with highest level of care at each hospital (per American Academy of Pediatrics classification $^{12}$ ): a level IV NICU for the university teaching hospital, a level III NICU at the teaching community hospital, and a level II specialty care nursery at the nonteaching commu- nity hospital. Antibiotic exposure included administration of antibiotics for sepsis screening ( $<3$ days) and for presumed/ proven sepsis ( $>3$ days). The need for respiratory support was defined as oxygen use (hood or nasal cannula), nasal continuous positive airway pressure, and/or mechanical ventilation at any time during the hospitalization. We defined hypoglycemia as a blood glucose value $\leq 45 \mathrm{mg} / \mathrm{dL}$ recorded in nursing flow sheets or laboratory results.

\section{Statistical Analysis}

We used chi-square or Fisher exact tests for analysis of categorical data and one-way analysis of variance or Kruskal-Wallis tests for analysis of continuous data. We used logistic regression analysis to examine the association between hospital and categorical outcomes. For the analysis of length of stay, we used zero-truncated negative binomial regression due to over-dispersion and the absence of zero values. Results of the negative binomial regression are expressed as estimated marginal mean days with 95\% confidence intervals. We used multivariable analyses to adjust for maternal and newborn risk factors found to have significant differences across sites after bivariate analysis or considered a priori as risk factors for the outcome. For logistic regression models, we used backward selection to generate a final model. We used the likelihood ratio tests to compare full and reduced zero-truncated negative binomial regression models. Because of the small sample size and concerns about the reliability of the models when incorporating numerous covariates, we did not include indication for delivery in the initial multivariable models. However, further analysis including indication for delivery in the multivariable models produced similar results. All analyses were conducted using STATA statistical software, version 12 (STATA, College Station, TX). The institutional review boards with oversight at each site approved this study.

\section{Results}

A total of 22,383 births occurred at the three study hospitals during the study period, of which 1,479 (6.6\%) were late preterm (-Fig. 1). We reviewed 352 maternal charts and 426 late preterm newborn charts for inclusion in the study; 95

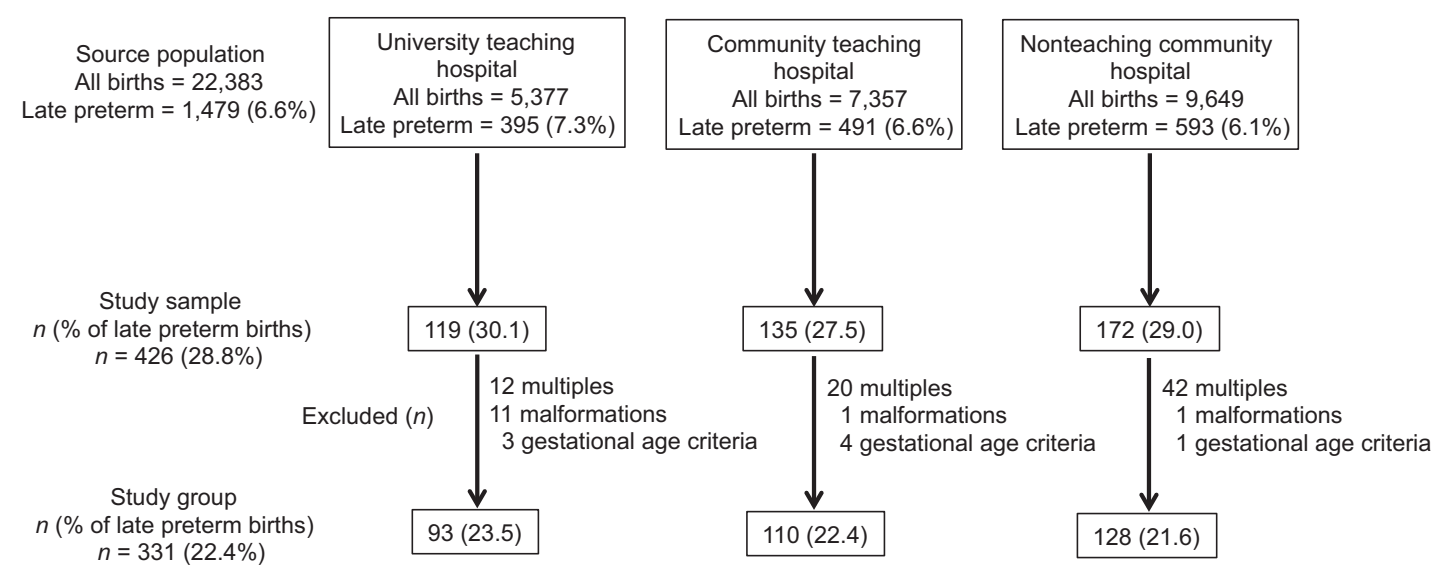

Fig. 1 Study flow diagram. 
newborns met exclusion criteria ( 74 for multiple gestation, 13 for major congenital anomalies, and 8 for gestational age criteria). We analyzed maternal and newborn data from 331 singleton late preterm newborns (22.4\% of all late preterm births), 93 (28.1\%) from a university teaching hospital, 110 (33.2\%) from a teaching community hospital, and 128 (38.7\%) from a nonteaching community hospital. There were no deaths in the study group before discharge and all newborns were discharged home.

\section{Study Group Characteristics}

The majority of late preterm births in the study group occurred at 36 weeks' gestation ( $51.4 \%, n=170$ ); the mean (standard deviation) gestational age was 35.3 (0.8) weeks. We found few differences in demographic characteristics by gestational age (-Table 1). Mean birth weight was 2,677 g and correlated with advancing gestational age. More late preterm newborns at 34 weeks' gestation were exposed to antenatal corticosteroids compared with births at 35 and 36 weeks $(p<0.001)$. We did not find significant differences by gestational age for other characteristics, including associated maternal obstetrical and medical complications (data not shown).

We found several significant differences in demographic characteristics by hospital ( - Table 2 ). We did not find a difference in gestational age across hospitals; however, birth weight was lowest at the teaching community hospital and highest at the nonteaching community hospital. We found small differences in maternal age across sites and more late preterm births at the nonteaching community hospital were to non-Hispanic white women and women with private insurance $(p<0.001)$.

More late preterm births followed labor induction or cesarean without labor at the university teaching hospital compared with the teaching community hospital and nonteaching community hospital (60.2 vs. 38.2 vs. $48.4 \%$, $p=0.007$ ) (-Table 2). More women from the university teaching hospital had a history of chronic hypertension and received antenatal corticosteroids compared with the other two hospitals. We did not find statistically significant differences in other maternal characteristics across hospitals.

We found hospital differences in maternal obstetric risk factors. Late preterm births associated with isolated spontaneous labor or PPROM were more common at the teaching community hospital and nonteaching community hospital compared with the university teaching hospital (63.6 vs. 61.7 vs. $43.0 \%, p<0.05$ ) (-Table 3). We found fewer late preterm births associated with "other" complications at the teaching community hospital compared with the university and nonteaching community hospitals ( 1.8 vs. 16.1 vs. $9.4 \%, p<0.05$ ). The majority of births in the "other" category were associated with nonreassuring fetal status or oligohydramnios. We did not find significant differences among study hospitals in late preterm births associated with hypertensive disorders of pregnancy, placental abruption or previa, or elective/scheduled deliveries.

\section{Outcomes by Gestational Age and Level of Care}

Overall, $34.7 \%(n=115)$ of late preterm newborns in the study group were admitted to a NICU. NICU admission was inversely related to gestational age $(84.1 \%$ at 34 weeks vs. $29.6 \%$ at 35 weeks vs. $19.4 \%$ at 36 weeks, $p<0.001$ ). Median length of NICU stay was shorter as gestational age increased ( 7 days for 34 weeks, 3 days for 35 weeks, and 2 days for 36 weeks, $p<0.001$ ). Median length of stay was greater for late preterm newborns admitted to the NICU compared with those admitted to the newborn nursery ( 7 vs. 2 days, $p<0.001$ ) (-Table 4).

We found $20.2 \%$ ( $n=67$ ) of late preterm newborns in our study group were exposed to postnatal antibiotics during the birth hospitalization. Only late preterm newborns admitted to a NICU received antibiotics ( - Table 4 ). Among late preterm newborns exposed to antibiotics, $82.1 \%$ received $<3$ days of therapy for sepsis screening and $17.9 \%$ received $>3$ days of therapy for presumed or proven sepsis. Only one newborn had proven sepsis. Antibiotic exposure was more common in late preterm newborns at 34 weeks' gestation compared with 35 and 36 weeks (52.4 vs. 17.3 vs. 9.4\%, $p<0.001$ ).

Overall, $33.2 \%$ ( $n=110)$ of late preterm newborns in the study group received phototherapy. More late preterm newborns admitted to the NICU (58.3\%) received phototherapy compared with those admitted to the newborn nursery (19.9\%) (-Table 4). Phototherapy was more common at 34 weeks compared with 35 and 36 weeks (63.5 vs. 34.7 vs. $21.2 \%, p<0.001)$.

Among all late preterm newborns in the study group, $17.8 \%(n=59)$ received respiratory support and $26.9 \%$ $(n=89)$ had hypoglycemia. Use of respiratory support was more common at 34 weeks compared with 35 and 36 weeks ( 46.0 vs. 13.3 vs. $10.0 \%, p<0.001$ ). The presence of hypoglycemia did not differ significantly by gestational age.

\section{Outcomes by Hospital}

Admission to the NICU was more common at the university teaching hospital compared with the teaching community hospital and nonteaching community hospital (51.6 vs. 32.7 vs. $24.2 \%, p<0.001$ ). Among births at 34 weeks' gestation, $100 \%$ were admitted to the NICU at the university teaching hospital compared with $68.2 \%$ at the teaching community hospital and $85.0 \%$ at the nonteaching community hospital ( - Table 4). After adjusting for gestational age, birth weight, spontaneous labor, and cesarean delivery, we found lower odds of admission to the NICU at the teaching community hospital (odds ratio [OR], 0.35; 95\% confidence interval [CI], $0.17,0.71$ ) and nonteaching community hospital (OR, 0.26; $95 \% \mathrm{CI}, 0.13,0.52)$ compared with the university teaching hospital (-Table 5).

Antibiotic exposure was more common at the university teaching hospital compared with teaching community hospital and nonteaching community hospital (31.2 vs. 17.3 vs. $14.1 \%, p=0.005)$. The odds of antibiotic exposure were lowest at the teaching community hospital (OR, 0.34; 95\% $\mathrm{CI}, 0.14,0.86$ ) and nonteaching community hospital (OR, 0.25; $95 \% \mathrm{CI}, 0.09,0.67)$ after adjusting for gestational age, antenatal corticosteroids, spontaneous labor, and need for respiratory support ( $\mathbf{- T a b l e ~} \mathbf{5}$ ).

More late preterm newborns received phototherapy at the university teaching hospital compared with teaching 
Table 1 Cohort characteristics by gestational age $(n=331)$

\begin{tabular}{|c|c|c|c|c|c|}
\hline & 34 wk $(n=63)$ & 35 wk $(n=98)$ & 36 wk $(n=170)$ & Full cohort & $p$ value \\
\hline Birth weight (g), mean (SD) & $2,349(372)$ & $2,624(476)$ & $2,829(462)$ & $2,677(485)$ & $<0.001$ \\
\hline Male, $n(\%)$ & $37(58.7)$ & $54(55.1)$ & $94(55.3)$ & $185(55.9)$ & 0.88 \\
\hline Maternal age (y), mean (SD) & $29(6.6)$ & $28(6.2)$ & $29(6.1)$ & $29(6.2)$ & 0.82 \\
\hline \multicolumn{6}{|l|}{ Race, $n(\%)$} \\
\hline White & $31(49.2)$ & $48(49.0)$ & $80(47.1)$ & $159(48.0)$ & \multirow[t]{3}{*}{0.84} \\
\hline Black & $13(20.6)$ & $26(26.5)$ & 39 (22.9) & $78(23.6)$ & \\
\hline Hispanic/other & $19(30.2)$ & $24(24.5)$ & $51(30.0)$ & $94(28.4)$ & \\
\hline \multicolumn{6}{|l|}{ Insurance type, n (\%) } \\
\hline Uninsured & $18(28.6)$ & $22(22.5)$ & $41(24.1)$ & $81(24.5)$ & \multirow[t]{3}{*}{0.88} \\
\hline Public & $16(25.4)$ & $31(31.6)$ & $48(28.2)$ & $95(28.7)$ & \\
\hline Private & $29(46.0)$ & 45 (45.9) & $81(47.7)$ & $155(46.8)$ & \\
\hline Prenatal care, $n(\%)$ & $53(84.1)$ & $86(87.8)$ & $155(91.2)$ & $294(88.8)$ & 0.38 \\
\hline Primiparous, $n(\%)$ & $19(30.2)$ & $32(32.7)$ & $53(31.2)$ & $104(31.4)$ & 0.94 \\
\hline Previous cesarean, $n(\%)$ & $14(22.2)$ & $15(15.3)$ & $42(24.7)$ & $71(21.5)$ & 0.19 \\
\hline \multicolumn{6}{|l|}{ Type of labor, $n(\%)$} \\
\hline Spontaneous & $28(44.4)$ & $59(60.2)$ & $84(49.4)$ & $171(51.7)$ & \multirow[t]{2}{*}{0.10} \\
\hline Induced/cesarean without labor & $35(55.6)$ & $39(39.8)$ & $86(50.6)$ & $160(48.3)$ & \\
\hline Cesarean delivery, $n$ (\%) & $28(44.4)$ & $27(27.6)$ & $68(40.0)$ & $123(37.2)$ & 0.05 \\
\hline Diabetes, $n(\%)$ & $14(22.2)$ & $10(10.2)$ & $26(15.3)$ & $50(15.1)$ & 0.12 \\
\hline Chronic hypertension, $n(\%)$ & $7(11.1)$ & $7(7.1)$ & $10(5.9)$ & $24(7.3)$ & 0.40 \\
\hline Antenatal corticosteroids, $n(\%)$ & $20(31.8)$ & $13(13.3)$ & $8(4.7)$ & $41(12.4)$ & $<0.001$ \\
\hline Chorioamnionitis, $n$ (\%) & $2(3.2)$ & $4(4.1)$ & $3(1.8)$ & $9(2.7)$ & 0.49 \\
\hline
\end{tabular}

Abbreviations: SD, standard deviation; wk, weeks; y, years.

community hospital and nonteaching community hospital ( 51.6 vs. 25.5 vs. $26.6 \%, p<0.001$ ). After adjusting for gestational age, birth weight, and NICU admission, the odds of phototherapy exposure were lowest at the teaching community hospital (OR, 0.32; 95\% CI, 0.17, 0.63) and nonteaching community hospital (OR, 0.42; 95\% CI, 0.22, 0.80) (- Table 5). Among infants admitted to the newborn nursery, phototherapy use was more common at the university teaching hospital compared with teaching community hospital and nonteaching community hospital (35.6 vs. 12.2 vs. $18.6 \%, p<0.001$ ). Need for respiratory support and hypoglycemia did not vary across hospitals.

Unadjusted length of stay was the same at the university teaching hospital and community teaching hospital despite more frequent admission to the NICU at the university teaching hospital (-Table 5). We found the shortest unadjusted mean length of stay at the nonteaching community hospital ( 3.7 vs. 4.9 days for the other hospital types, $p=0.02$ for both comparisons). Length of stay was shortest at the university teaching hospital and longest at the teaching community hospital after adjusting for birth weight, cesarean delivery, phototherapy, NICU admission, and need for respiratory support (- Table $\mathbf{5}$ ).

\section{Discussion}

We identified institutional variation in late preterm newborn admission to the NICU, exposure to antibiotics, phototherapy, and length of stay. Institution-specific practices for late preterm newborn care (e.g., gestational age threshold for NICU admission) likely explain some of this variation. Variation in care for late preterm newborns during the birth hospitalization may affect subsequent morbidity and health care utilization during the first few weeks or months after birth.

Approximately $40 \%$ of late preterm newborns are admitted to a NICU at birth. ${ }^{13-16}$ The level of care for late preterm newborns is determined by a combination of clinical factors (e.g., respiratory distress, temperature instability), institutional factors (e.g., NICU admission criteria, available level of care), and provider factors (comfort level, experience). Level of care for late preterm newborns influences the duration of the birth hospitalization and readmission risk. ${ }^{17-19}$ Late preterm newborns admitted to a NICU have longer lengths of stay but lower readmission risk compared with those cared for in a newborn nursery. ${ }^{17}$ Institutional gestational age thresholds for NICU admission vary, however, few studies 
Table 2 Cohort characteristics by hospital $(n=331)$

\begin{tabular}{|c|c|c|c|c|c|}
\hline & $\begin{array}{l}\text { University } \\
\text { teaching } \\
(n=93)\end{array}$ & $\begin{array}{l}\text { Teaching } \\
\text { community } \\
(n=110)\end{array}$ & $\begin{array}{l}\text { Nonteaching } \\
\text { community } \\
(n=128)\end{array}$ & Full cohort & $p$ value \\
\hline GA (wk), mean (SD) & $35.3(0.8)$ & $35.2(0.8)$ & $35.4(0.7)$ & $35.3(0.8)$ & 0.22 \\
\hline Birth weight (g), mean (SD) & $2,674(513)$ & 2,591 (467) & $2,754(470)$ & $2,677(485)$ & 0.03 \\
\hline Male, $n(\%)$ & $55(59.1)$ & $53(48.2)$ & $77(60.2)$ & 185 (55.9) & 0.14 \\
\hline Maternal age (y), mean (SD) & $29(6.6)$ & $27(6.0)$ & $30(5.9)$ & $29(6.2)$ & 0.002 \\
\hline \multicolumn{6}{|l|}{ Race, $n(\%)$} \\
\hline Non-Hispanic white & 39 (41.9) & $39(35.5)$ & $81(63.3)$ & $159(48.0)$ & \multirow[t]{3}{*}{$<0.001$} \\
\hline Non-Hispanic black & $11(11.8)$ & $38(34.6)$ & $29(22.7)$ & $78(23.6)$ & \\
\hline Hispanic/other & $43(46.2)$ & $33(30.0)$ & $18(14.1)$ & $94(28.4)$ & \\
\hline \multicolumn{6}{|l|}{ Insurance type, n (\%) } \\
\hline Uninsured & $35(37.6)$ & $40(36.4)$ & $6(4.7)$ & $81(24.5)$ & \multirow[t]{3}{*}{$<0.001$} \\
\hline Public & $31(33.3)$ & $36(32.7)$ & $28(21.9)$ & $95(28.7)$ & \\
\hline Private & $27(29.0)$ & $34(30.9)$ & $94(73.4)$ & $155(46.8)$ & \\
\hline Prenatal care, $n(\%)$ & $79(85.0)$ & $94(85.5)$ & $121(94.5)$ & $294(88.8)$ & 0.09 \\
\hline Primiparous, $n(\%)$ & $23(24.7)$ & $35(31.8)$ & $46(35.9)$ & $104(31.4)$ & 0.21 \\
\hline Previous cesarean, $n(\%)$ & $23(24.7)$ & $22(20.0)$ & $26(20.3)$ & $71(21.5)$ & 0.66 \\
\hline \multicolumn{6}{|l|}{ Type of labor, $n(\%)$} \\
\hline Spontaneous & $37(39.8)$ & $68(61.8)$ & $66(51.6)$ & $171(51.7)$ & \multirow[t]{2}{*}{0.007} \\
\hline Induced/cesarean without labor & $56(60.2)$ & $42(38.2)$ & $62(48.4)$ & $160(48.3)$ & \\
\hline Cesarean, $n(\%)$ & $36(38.7)$ & $37(33.6)$ & $50(39.1)$ & $123(37.2)$ & 0.64 \\
\hline Diabetes, $n(\%)$ & $15(16.1)$ & $17(15.5)$ & $18(14.1)$ & $50(15.1)$ & 0.91 \\
\hline Chronic hypertension, $n$ (\%) & $13(14.0)$ & $6(5.5)$ & $5(3.9)$ & $24(7.3)$ & 0.02 \\
\hline Antenatal corticosteroids, $n(\%)$ & $19(20.4)$ & $12(10.9)$ & $10(7.8)$ & $41(12.4)$ & 0.02 \\
\hline Chorioamnionitis, $n(\%)$ & $1(1.1)$ & $4(3.6)$ & $4(3.1)$ & $9(2.7)$ & 0.53 \\
\hline
\end{tabular}

Abbreviations: GA, gestational age; SD, standard deviation; wk, weeks; y, years.

Table 3 Obstetric and medical complications by hospital $(n=331), n(\%)$

\begin{tabular}{|c|c|c|c|c|}
\hline & $\begin{array}{l}\text { University teaching } \\
(n=93)\end{array}$ & $\begin{array}{l}\text { Teaching community } \\
(n=110)\end{array}$ & $\begin{array}{l}\text { Nonteaching community } \\
(n=128)\end{array}$ & Full cohort \\
\hline Spontaneous labor/PPROMa & $40(43.0)$ & $70(63.6)$ & $79(61.7)$ & $189(57.1)$ \\
\hline Hypertensive disorders of pregnancy & $27(29.0)$ & $22(20.0)$ & $22(17.2)$ & $71(21.5)$ \\
\hline Placental abruption/previa & $7(7.5)$ & $11(10.0)$ & $9(7.0)$ & $27(8.2)$ \\
\hline Elective/scheduled delivery & $4(4.3)$ & $5(4.6)$ & $6(4.7)$ & $15(4.5)$ \\
\hline Other/unknownab & $15(16.1)$ & $2(1.8)$ & $12(9.4)$ & $29(8.8)$ \\
\hline
\end{tabular}

Abbreviation: PPROM, preterm premature rupture of membranes.

${ }^{a} p<0.05$.

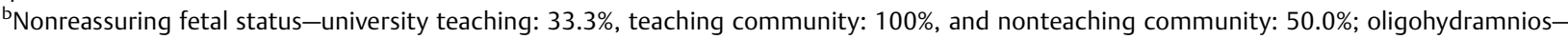
university teaching: $40.0 \%$, teaching community: $0 \%$, and nonteaching community: $25.0 \%$.

directly address this issue., ${ }^{5,10,11}$ Institutional differences in practices and policies might explain some of the variation in NICU admission found in this study. The university teaching hospital was the only study hospital with a specific gestational age threshold for admission to the NICU. Overall, the range of NICU admission observed across hospitals in our study is consistent with data from previously published single center studies. ${ }^{13,15,16}$

We found variation in antibiotic use by level of care and across hospitals. Overall, antibiotic use in the cohort was comparable to that seen in other studies. ${ }^{15,16,20-22}$ However, we found that only late preterm newborns admitted to the 
Table 4 Outcomes by level of care and hospital $(n=331)$

\begin{tabular}{|c|c|c|c|c|}
\hline & $\begin{array}{l}\text { University teaching } \\
(n=93)\end{array}$ & $\begin{array}{l}\text { Teaching community } \\
(n=110)\end{array}$ & $\begin{array}{l}\text { Nonteaching community } \\
(n=128)\end{array}$ & All sites \\
\hline NBN admission, $n(\%)^{\mathrm{a}}$ & $45(48.4)$ & $74(67.3)$ & $97(75.8)$ & $216(65.3)$ \\
\hline NICU admission, $n(\%)^{\mathrm{a}}$ & $48(51.6)$ & $36(32.7)$ & $31(24.2)$ & $115(34.7)$ \\
\hline \multicolumn{5}{|l|}{ NICU admission by GA, $n(\%)$} \\
\hline $34 \mathrm{wk}$ & $21(100)$ & $15(68.2)$ & $17(85.0)$ & $53(84.1)$ \\
\hline 35 wk & $11(45.8)$ & $11(28.2)$ & $7(20.0)$ & $29(29.6)$ \\
\hline $36 \mathrm{wk}$ & $16(33.3)$ & $10(20.4)$ & $7(9.6)$ & $33(19.4)$ \\
\hline \multicolumn{5}{|l|}{ Admitted to the NICU } \\
\hline Antibiotics, $n(\%)$ & $29(60.4)$ & $19(52.8)$ & $19(61.3)$ & $67(58.3)$ \\
\hline Phototherapy, $n$ (\%) & $32(66.7)$ & $19(52.8)$ & $16(51.6)$ & $67(58.3)$ \\
\hline LOS (d), median (25th, 75th) & $6(3,12)$ & $8(5,12)$ & $7(5,10)$ & $7(4,11)$ \\
\hline Hypoglycemia, $n(\%)$ & $18(37.5)$ & $13(36.1)$ & $9(29.0)$ & $40(34.8)$ \\
\hline Respiratory support, $n$ (\%) & $24(50.0)$ & $17(47.2)$ & $18(58.1)$ & $59(51.3)$ \\
\hline \multicolumn{5}{|l|}{ Admitted to NBN } \\
\hline Antibiotics, $n(\%)$ & 0 & 0 & 0 & 0 \\
\hline Phototherapy, $n(\%)^{a}$ & $16(35.6)$ & $9(12.2)$ & $18(18.6)$ & 43 (19.9) \\
\hline LOS (d), median (25th, 75th) & $2(1,3)$ & $2(2,3)$ & $2(2,3)$ & $2(2,3)$ \\
\hline Hypoglycemia, n (\%) & $10(22.2)$ & $15(20.3)$ & $24(24.7)$ & $49(22.7)$ \\
\hline Respiratory support, $n$ (\%) & 0 & 0 & 0 & 0 \\
\hline
\end{tabular}

Abbreviations: d, days; GA, gestational age; LOS, length of stay; NBN, newborn nursery; NICU, neonatal intensive care unit; wk, weeks. ${ }^{\mathrm{a}} \mathrm{p}<0.05$.

Table 5 Outcomes by hospital

\begin{tabular}{|l|l|l|l|}
\hline & University teaching & Teaching community & Nonteaching community \\
\hline NICU admission, OR $(95 \% \mathrm{Cl})^{\mathrm{ab}}$ & Reference & $0.35(0.17,0.71)$ & $0.26(0.13,0.52)$ \\
\hline Antibiotics, OR $(95 \% \mathrm{Cl})^{\mathrm{ac}}$ & Reference & $0.34(0.14,0.86)$ & $0.25(0.09,0.67)$ \\
\hline Phototherapy, OR $(95 \% \mathrm{Cl})^{\text {ad }}$ & Reference & $0.32(0.17,0.63)$ & $0.42(0.22,0.80)$ \\
\hline Unadjusted LOS, ${ }^{\mathrm{e}}$ mean days $(95 \% \mathrm{Cl})$ & $4.9(4.0,5.9)$ & $4.9(4.0,5.7)$ & $3.7(3.1,4.2)$ \\
\hline Adjusted LOS, mean days $(95 \% \mathrm{Cl})$ & $2.9(2.5,3.2)$ & $3.8(3.4,4.2)$ & $3.3(2.9 .3 .6)$ \\
\hline
\end{tabular}

Abbreviations: $\mathrm{Cl}$, confidence interval; LOS, hospital length of stay expressed as predicted marginal mean estimates $(95 \% \mathrm{Cl})$ from truncated negative binomial regression; NICU, neonatal intensive care unit; OR, odds ratio.

${ }^{a} p<0.05$.

${ }^{\mathrm{b}}$ Adjusted for gestational age, birth weight, cesarean delivery, and spontaneous labor.

${ }^{\mathrm{c}}$ Adjusted for gestational age, spontaneous labor, antenatal corticosteroids, and respiratory support.

${ }^{\mathrm{d}}$ Adjusted for gestational age, birth weight, and NICU admission.

eUniversity and teaching community versus nonteaching community, $p=0.02$.

${ }^{\mathrm{f}}$ Adjusted for birth weight, cesarean delivery, phototherapy, NICU admission, respiratory support; university versus teaching community, $p<0.001$; university versus nonteaching community, $p=0.08$; teaching community versus nonteaching community, $p=0.048$.

NICU received antibiotics. This finding was not solely related to hospital policy, as the nonteaching community hospital was the only hospital in our study that required admission to the NICU if antibiotics were prescribed. Few studies differentiate antibiotic exposure in late preterm newborns by level of care. ${ }^{22}$ In addition to a higher concern for sepsis in newborns admitted to a NICU, differences in practice or "culture" (e.g., threshold for sepsis screening) between levels of care likely contribute to greater antibiotic use in the NICU. Greater antibiotic use in the NICU may result in potential overuse of antibiotics when admission to the NICU is not exclusively determined by clinical factors but rather by institutional practices. More NICU admissions at the university teaching hospital and a lower threshold to start antibiotics in the NICU 
are likely explanations for variation in antibiotic use among late preterm newborns in this study.

Hyperbilirubinemia is one of the most common morbidities of the late preterm newborn and a common reason for readmission. ${ }^{17,19,23}$ Differences in the management of hyperbilirubinemia, including bilirubin testing and phototherapy thresholds, likely influence readmission risk. ${ }^{24-26}$ Phototherapy use among late preterm newborns in this study was higher compared with previous studies. ${ }^{15,16,21,22,27}$ The differences in phototherapy use across hospitals in our study appeared to be due to variation in phototherapy use in late preterm newborns cared for in the newborn nursery. It is possible that differences in phototherapy thresholds, frequency of bilirubin level checks, and presence of trainees might explain some of this variation. Published guidelines from the American Academy of Pediatrics on the management of hyperbilirubinemia apply to newborns of 35 weeks' gestation or greater, which may result in more variability in management for newborns at 34 weeks' gestation. ${ }^{28}$

Our results suggest that late preterm newborn length of stay is influenced not only by physiologic risk factors such as gestational age but also by factors subject to practice variation (e.g., phototherapy use, NICU admission). Previous studies have found institutional and regional differences in postmenstrual age at discharge among moderately preterm newborns (30-34 $4^{6 / 7}$ weeks' gestation) that are likely not due to differences in illness severity. ${ }^{4,5,8}$ Few studies have examined variation in length of stay among late preterm newborns. ${ }^{29}$ Length of stay, NICU admission, and phototherapy use in late preterm newborns during the birth hospitalization are likely to have implications for health care utilization after discharge (e.g., outpatient care and readmissions). Greater intensity of care for some late preterm newborns during the birth hospitalization (e.g., NICU admission) might result in fewer outpatient visits or readmissions. For other infants, a greater intensity of care may increase length of stay and cost without any overall benefit. The sample size of our study limits our ability to determine the "ideal" level of care and length of stay for late preterm newborns that would optimize outcomes.

Strengths of this study include the multicenter nature of the cohort and the availability of detailed maternal and obstetric data. To create a more homogeneous group at each site, particularly at the university teaching hospital, we only included inborn infants. We attempted to prioritize the use of objective outcomes (e.g., NICU admission, need for respiratory support) rather than clinical diagnoses which are more susceptible to measurement bias. We acknowledge the limitations of the small sample size at each site and the hypothesis generating nature of this study. Despite the multicenter nature of this study, the geographic proximity of the three participating hospitals may limit generalizability. We did attempt to control for potential differences in illness severity in the multivariable analysis, but the risk of unmeasured confounders remains. Feeding difficulties are a common reason for the continued hospitalization of late preterm newborns beyond the recommended minimum of 48 hours. Data on documentation of feeding problems were variable by site, thus we were not able to examine how feeding difficul- ties might have influenced outcomes, such as length of stay. Because of the small sample size, we did not examine differences in outcomes based on indication for delivery. We were also unable to examine outcomes beyond the birth hospitalization (e.g., readmissions, outpatient visits). An examination of these outcomes is the purpose of further planned research.

\section{Conclusion}

We found institutional variation in outcomes of late preterm newborns. Variation in outcomes might be due to differences in institutional practices (e.g., gestational age threshold for NICU admission) and not exclusively determined by clinical risk factors. Differences in practice during the birth hospitalization may affect outcomes and health care utilization after discharge. Compared with more premature infants who routinely receive intensive care, the birth hospitalization for late preterm newborns intersects different levels of care: intensive care and routine newborn nursery. Only in recent years have morbidities of late preterm birth been broadly recognized. Neonatal practice has now started to address the specific needs of the late preterm population. However, higher quality evidence is needed to guide best practice for care of the late preterm newborn during the birth hospitalization and optimize subsequent outcomes.

\section{Acknowledgments}

We would like to thank the research staff at participating hospitals for their invaluable help with the data collection for this study.

\section{Conflict of Interest}

The authors declare no conflict of interest.

\section{References}

1 Hamilton BE, Martin JA, Ventura SJ. Births: Preliminary Data for 2009. In: National Vital Statistics Reports. Hyattsville, MD: National Center for Health Statistics; 2010

2 Engle WA, Tomashek KM, Wallman C; Committee on Fetus and Newborn, American Academy of Pediatrics. "Late-preterm" infants: a population at risk. Pediatrics 2007;120(6):1390-1401

3 Zupancic JA, Richardson DK. Characterization of the triage process in neonatal intensive care. Pediatrics 1998;102(6): $1432-1436$

4 Profit J, Zupancic JA, McCormick MC, et al. Moderately premature infants at Kaiser Permanente Medical Care Program in California are discharged home earlier than their peers in Massachusetts and the United Kingdom. Arch Dis Child Fetal Neonatal Ed 2006;91(4): F245-F250

5 Roblin DW, Richardson DK, Thomas E, et al. Variation in the use of alternative levels of hospital care for newborns in a managed care organization. Health Serv Res 2000;34(7):1535-1553

6 Lee SK, McMillan DD, Ohlsson A, et al. Variations in practice and outcomes in the Canadian NICU network: 1996-1997. Pediatrics 2000;106(5):1070-1079

7 Spitzer AR, Kirkby S, Kornhauser M. Practice variation in suspected neonatal sepsis: a costly problem in neonatal intensive care. J Perinatol 2005;25(4):265-269 
8 Altman M, Vanpée M, Cnattingius S, Norman M. Moderately preterm infants and determinants of length of hospital stay. Arch Dis Child Fetal Neonatal Ed 2009;94(6):F414-F418

9 Eichenwald EC, Blackwell M, Lloyd JS, Tran T, Wilker RE, Richardson DK. Inter-neonatal intensive care unit variation in discharge timing: influence of apnea and feeding management. Pediatrics 2001;108(4):928-933

10 Whyte RK. Neonatal management and safe discharge of late and moderate preterm infants. Semin Fetal Neonatal Med 2012; 17(3):153-158

11 Gyamfi-Bannerman C, Fuchs KM, Young OM, Hoffman MK. Nonspontaneous late preterm birth: etiology and outcomes. Am J Obstet Gynecol 2011;205(5):e1-e6

12 American Academy of Pediatrics Committee on Fetus And Newborn. Levels of neonatal care. Pediatrics 2012;130(3):587-597

13 Lubow JM, How HY, Habli M, Maxwell R, Sibai BM. Indications for delivery and short-term neonatal outcomes in late preterm as compared with term births. Am J Obstet Gynecol 2009;200(5): e30-e33

14 Hibbard JU, Wilkins I, Sun L, et al; Consortium on Safe Labor. Respiratory morbidity in late preterm births. JAMA 2010; 304(4):419-425

15 Melamed N, Klinger G, Tenenbaum-Gavish K, et al. Short-term neonatal outcome in low-risk, spontaneous, singleton, late preterm deliveries. Obstet Gynecol 2009;114(2 Pt 1):253-260

16 Kitsommart R, Janes M, Mahajan V, et al. Outcomes of late-preterm infants: a retrospective, single-center, Canadian study. Clin Pediatr (Phila) 2009;48(8):844-850

17 Escobar GJ, Greene JD, Hulac P, et al. Rehospitalisation after birth hospitalisation: patterns among infants of all gestations. Arch Dis Child 2005;90(2):125-131

18 Escobar GJ, Joffe S, Gardner MN, Armstrong MA, Folck BF, Carpenter DM. Rehospitalization in the first two weeks after discharge from the neonatal intensive care unit. Pediatrics 1999;104(1):e2
19 Jain S, Cheng J. Emergency department visits and rehospitalizations in late preterm infants. Clin Perinatol 2006;33(4):935-945, abstract xi

20 Wang ML, Dorer DJ, Fleming MP, Catlin EA. Clinical outcomes of near-term infants. Pediatrics 2004;114(2):372-376

21 McIntire DD, Leveno KJ. Neonatal mortality and morbidity rates in late preterm births compared with births at term. Obstet Gynecol 2008;111(1):35-41

22 Vachharajani AJ, Dawson JG. Short-term outcomes of late preterms: an institutional experience. Clin Pediatr (Phila) 2009;48(4):383-388

23 Teune MJ, Bakhuizen S, Gyamfi Bannerman C, et al. A systematic review of severe morbidity in infants born late preterm. Am J Obstet Gynecol 2011;205(4):e1-e9

24 Kuzniewicz MW, Escobar GJ, Newman TB. Impact of universal bilirubin screening on severe hyperbilirubinemia and phototherapy use. Pediatrics 2009;124(4):1031-1039

25 Petersen JR, Okorodudu AO, Mohammad AA, Fernando A, Shattuck KE. Association of transcutaneous bilirubin testing in hospital with decreased readmission rate for hyperbilirubinemia. Clin Chem 2005;51(3):540-544

26 Eggert LD, Wiedmeier SE, Wilson J, Christensen RD. The effect of instituting a prehospital-discharge newborn bilirubin screening program in an 18-hospital health system. Pediatrics 2006;117(5): e855-e862

27 Bastek JA, Sammel MD, Paré E, Srinivas SK, Posencheg MA, Elovitz MA. Adverse neonatal outcomes: examining the risks between preterm, late preterm, and term infants. Am J Obstet Gynecol 2008; 199(4):e1-e8

28 American Academy of Pediatrics Subcommittee on Hyperbilirubinemia. Management of hyperbilirubinemia in the newborn infant 35 or more weeks of gestation. Pediatrics 2004;114(1): 297-316

29 Goyal NK, Fager C, Lorch SA. Adherence to discharge guidelines for late-preterm newborns. Pediatrics 2011;128(1):62-71 